\title{
From Crowds to Collaborators: Initiating Effort \& Catalyzing Interactions Among Online Creative Workers
}

\section{Citation}

Boudreau, Kevin, Patrick Gaule, Karim R. Lakhani, Christoph Riedl, and Anita Williams Woolley. "From Crowds to Collaborators: Initiating Effort \& Catalyzing Interactions Among Online Creative Workers." Harvard Business School Working Paper, No. 14-060, January 2014.

\section{Permanent link}

http://nrs.harvard.edu/urn-3:HUL.InstRepos:12111352

\section{Terms of Use}

This article was downloaded from Harvard University's DASH repository, and is made available under the terms and conditions applicable to Open Access Policy Articles, as set forth at http:// nrs.harvard.edu/urn-3:HUL.InstRepos:dash.current.terms-of-use\#OAP

\section{Share Your Story}

The Harvard community has made this article openly available. Please share how this access benefits you. Submit a story. 


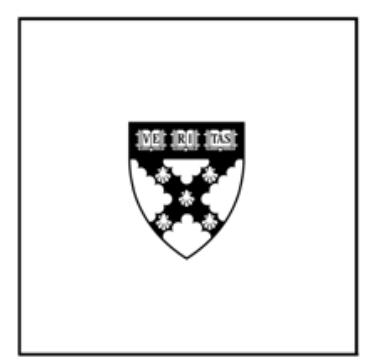

\title{
From Crowds to Collaborators: Initiating Effort \& Catalyzing Interactions Among Online Creative Workers
}

\author{
Kevin J. Boudreau \\ Patrick Gaule \\ Karim R. Lakhani \\ Christoph Riedl \\ Anita Williams Woolley
}

\section{Working Paper}

14-060

January 23, 2014

Copyright (C) 2014 by Kevin J. Boudreau, Patrick Gaule, Karim R. Lakhani, Christoph Riedl, and Anita Williams Woolley

Working papers are in draft form. This working paper is distributed for purposes of comment and discussion only. It may not be reproduced without permission of the copyright holder. Copies of working papers are available from the author. 


\title{
From Crowds to Collaborators: Initiating Effort \& Catalyzing Interactions Among Online Creative Workers
}

\author{
Kevin J. Boudreau, Patrick Gaule, Karim R. Lakhani, Christoph Riedl, \\ Anita Williams Woolley*
}

\begin{abstract}
Online collaborative platforms have emerged as a complementary approach to traditional organizations for coordinating the collective efforts of creative workers. However, it is surprising that they result in any productive output as individuals often work without direct monetary incentives while collaborating with unknown others. In this paper, we distinguish the conditions necessary for eliciting effort from those affecting the quality of interdependent teamwork. We consider the role of incentives versus social processes in catalyzing collaboration. We test our hypotheses using a unique data set of 260 individuals randomly assigned to 52 teams tasked with developing working solutions to a complex innovation problem over 10 days, with varying monetary incentives. We find that levels of effort are driven by cash incentives and the presence of other interacting teammates. The level of collaboration, by contrast, was not sensitive to cash incentives. Instead, individuals increased their communication if teammates were also actively participating. Additionally, team performance is uniquely driven by the level of emergent interdependence, as indexed by the diversity of topics discussed and the temporal coordination of activity in short focused time periods. Our results contribute to the literature on how alternative organizational forms can be designed to solve complex innovation tasks.
\end{abstract}

Keywords: Online platforms, collaboration, teams, interdependence, motivation and incentives, text analysis, temporal coordination.

* Authors are listed in alphabetical order and contributed equally to the work. Kevin J. Boudreau, London Business School \& Harvard Institute for Quantitative Social Science (kboudreau@london.edu); Patrick Gaule, CERGE-EI (pgaule@cerge-ei.cz); Karim R. Lakhani, Harvard Business School \& Harvard Institute for Quantitative Social Science (k@hbs.edu); Christoph Riedl, D'Amore-McKim School of Business, and College of Computer and Information Science, Northeastern University \& Institute for Quantitative Social Science, Harvard University (c.riedl@neu.edu); Anita Williams Woolley, Carnegie Mellon University, Tepper School of Business (awoolley@cmu.edu). Communication can be directed at CR. 
Organizing workers into teams is an enduring feature of most organizations (Jackson, Joshi, \& Erhardt, 2003). Across a wide range of activities, from effort-based manual labor to creative problem solving (Hackman, 2011, Hamilton, Nickerson, \& Owan, 2003, Wuchty, Jones, \& Uzzi, 2007), executives and managers deploy teams of workers to collectively accomplish tasks. Teams have been shown to be effective in tackling a wide range of task types and are superior to individual work under certain circumstances (Lazer \& Friedman, 2007). Teams have a particular advantage of integrating diverse knowledge of members and leveraging complementarities. However, extant literature also shows that teams require the right mix of incentives and coordination to accomplish tasks (Gardner, 2012).

While traditionally the organizational literature has focused on the factors explaining team success inside formal and established organizations (Ilgen et al., 2005, Haas, 2010), more recently, alternative online organizational forms have emerged (O'Mahony \& Ferraro, 2007, Dahlander \& O’Mahony, 2011, Yochai Benkler, 2013). These online “organizations" are now a major engine for knowledge development in a variety of domains (Kittur \& Kraut, 2008). Many online platforms involve collaboration and coordination among members to reach common goals, rather than just isolated actions by individual members. In this sense, they are “collaborative communities" (Murray \& O’Mahony, 2007, Seidel \& Stewart, 2011). For example, open source software development communities routinely coalesce into working groups who interact via online communication. While a large fraction of these projects fall fallow, those that have been successful have led open source communities to become a mainstream mode of software production. Analogously, groups of "modders," who build novel online video games by modifying existing commercial game platform engines, join into small teams interacting largely via online channels to complete their projects. These small transitory teams regularly form and disband, producing sophisticated game software along the way. Further, it is now possible for online labor markets, such as oDesk, to assemble teams within virtual workspaces to work on a software development project—as opposed to simply contracting jobs out to individuals. Contributions to Wikipedia also involve community members working virtually within subcommunities, in which multiple parties establish a consensus narrative around a given encyclopedic entry or topic (Faraj, Jarvenpaa, \& Majchrzak, 2011).

It might at first seem remarkable that these sorts of contexts sustain any level of effort and collaboration necessary for "collective intelligence" to emerge at all (Woolley et al., 2010). This is particularly so, given participation on these platforms is primarily voluntary with easy entry and exit through permeable organizational boundaries (O’Mahony \& Ferraro, 2007). Individuals often begin as utter strangers to one another, often from different parts of the world (Preece \& Shneiderman, 2009). Moreover, these strangers are meant to work in a context lacking interactive interpersonal richness, having few explicit commitment mechanisms, missing management oversight, and often lacking wider social context or socialization. The projects are also often transitory or short-lived. Thus the baseline conditions for any sort of collaboration and team effort towards a collective joint goal seem sparse at best and potentially fraught with failure. And yet, it is becoming increasingly common to observe large-scale mobilization of 
workers in these settings, incorporating thousands of projects and hundreds of thousands of workers (Benkler, 2006, von Krogh \& von Hippel, 2006, O’Mahony \& Ferraro, 2007, Faraj, Jarvenpaa, \& Majchrzak, 2011).

What triggers and transforms the anonymous "crowd" into productive collaborators? Is it possible to reliably elicit effort and collaboration among groups of strangers over online platforms so that they can be transformed into teams, absent the scaffolding of the traditional firm? And is it necessary for such groups to develop the high levels of emergent interdependence that characterizes successful teams in traditional organizations?

In this paper, we attempt to discern the basic ingredients behind successful online team collaborations outside the firm. In particular, we examine and attempt to distinguish the conditions necessary for eliciting effort from those affecting the quality of team products. Specifically, we consider two leading views in the elicitation of effort: first, the view predominant in economics, which links participation and effort levels to the presence of incentives; and second, a more socially orientated view of team interactions and productivity predominant to research on organizational behavior that links the level of participation to the perceived participation of others. We examine how these distinct sets of factors shape not only effort choices, but the extent of interactions and the collaborative style of work, as proxied by communication patterns. Apart from examining triggers of effort and interaction as such, we also evaluate evidence on how the emergence of collaboration relates to performance in terms of quality of the solutions developed. We do so via two important factors affecting the quality of team products - namely, the range and diversity of the information team members share with each other in their collaborative work (Crawford \& Haaland, 1972, Wuchty, Jones, \& Uzzi, 2007, Uzzi et al., 2013) and the temporal coordination evident in team members' contributions (Montoya-Weiss, Massey, \& Song, 2001). Both of these factors are integral pieces of the emergent interdependence that distinguishes co-acting groups from truly interdependent teams (Wageman \& Gordon, 2005, Caruso \& Woolley, 2008, Hackman, 2011) with the latter being the locus of true innovation in face-to-face contexts (Hackman, 2011).

This paper presents results from a field experiment in which 260 elite algorithm developers were randomly assigned to 52 teams of five. Each team was given the goal of creating a solution to a complex innovation problem posed by the US National Aeronautic and Space Administration (NASA) over the course of 10 days, through collaboration on an online platform. Teams were challenged with developing a computer program and algorithm to help in planning space mission parameters for astronaut health and safety. While prior research has been constrained to the use of observational data for studying teams in these environments, we take advantage of this unique setting to randomize the assignment of individuals to teams, and to randomly assign cash incentives, so as to allow us to draw causal inferences. The problem at hand and its implementation on the online platform also enabled us to obtain an objective, computer-derived measure of team performance by creating a quality score for each submission and to also get fine-grained measures of individual and team activity. This includes measures of 
effort, communication (frequency, timing, content), and participants' prior problem-solving performance.

In our analysis, we find that while cash incentives (a cash prize of $\$ 1,000$ ) have a clear effect on effort levels (roughly doubling hours worked) cash incentives did not produce significant increases in collaboration across team members. Nor did it even affect the likelihood that an individual would choose to participate at all. The effect focused only on the choice of continuous level of effort. Cash incentives do not appear to transform the nature work mode or to be sufficient to produce truly interactive collaborative on their own. Regarding socially emergent processes, we find evidence of a virtuous circle of effort and collaborative interactions taking place. The likelihood an individual chooses to participate relates to levels of teammates' communications and communications among teammates begot more communications and more effort. These patterns of reciprocating complementarities are consistent with the importance of setting productive social interactions and dynamics into motion in order to catalyze collaboration (Bettenhausen \& Murnighan, 1985, Ginnett, 1993, Ericksen \& Dyer, 2004), even in this rather weak social context.

Our second major finding regarding the performance heterogeneity among teams reveals that high levels of emergent interdependence are in fact important, even in this sparse social context. This is revealed by the importance of two key factors: the diversity of information exchanged within a team and the level of temporal coordination within the team, and the connections of both factors with performance. On the one hand, we find that an increase in the diversity of information discussed by team members is correlated with improved solution performance, which points to the salience of encouraging diversity in team-based problem solving settings. On the other hand, we also find that temporal coordination of team activity, i.e., the degree to which team members concentrated their communication and work effort during relatively contained time periods, despite variance in time zones, versus spreading them out over time, was linked to higher solution performance. Both diversity of information and temporal coordination of work remained significant predictors of performance even when controlling for the influence of cash incentives and the skill level of individual contributors, which were not significant. Hence absent a centralized manager or an appointed/assigned leader, success at online collaboration is particularly sensitive to the conditions enabling collective intelligence to develop within the team.

\section{External Online Collaboration and Teams}

The appeal of making use of external online collaborations is high and growing (O’Mahony \& Ferraro, 2007). Online contests and peer production communities provide the possibility of benefiting from a broader array of expertise and resources than any one organization can reasonably house (Jeppesen \& Lakhani, 2010, Boudreau \& Lakhani, 2013). However, we also know that online communities experience a relatively high level of attrition and failure (Butler et al., 2005), suggesting that, as with traditional organizations, they need to address the issues of motivation and coordination. 
At the most fundamental level, external online collaborations need to offer some sort of incentives to individuals for the elicitation of effort towards a common shared goal (Lerner \& Tirole, 2005). However, as the extant literature on online collaboration has shown, the scope for incentives is quite broad with a variety of both explicit and implicit rewards for participation (Lakhani \& Wolf, 2005, von Krogh et al., 2012). Beyond incentives for active participation and the exertion of effort, research on teams in general has shown that shared task accomplishment is highly dependent on a virtuous cycle of ongoing participation by other team members, i.e., active and visible participation by one member will beget more participation by others (Frey \& Meier, 2004). Thus, ongoing participation by any one individual will be highly sensitive to visible participation by others and either a cascade of conditional cooperation will take hold or teams may not gel if other members fail to reciprocate.

A second issue to resolve in external online collaboration is the level of interdependence that should characterize work. Online communities often function best with problems or tasks that can be modularized and completed less interdependently (Olson \& Olson, 2014). Independence (as opposed to interdependence) of ideas and contributions often lead to the highest levels of creativity (Paulus, 2000) and a broader sample of solutions from which to select (Nelson, 1959, Surowiecki \& Silverman, 2007). However, in organizational settings, teams that operate with a lower level of interdependence than is optimal often underperform more collaborative teams (Hackman, 2011). The ideal combination is a high level of diversity of information, coupled with the high levels of integration that can be accomplished through interdependent collaboration. Therefore, one of the primary reasons to deploy teams to solve problems is the ability to solicit and integrate a diverse range of knowledge inputs to the problem at hand (Reagans \& Zuckerman, 2001, Reagans, Zuckerman, \& McEvily, 2004, Gibson \& Gibbs, 2006, Pieterse, van Knippenberg, \& van Dierendonck, 2012, Shin et al., 2012). Indeed the secular rise of teams over individuals in conducting scientific and academic exploration has been attributed to the necessity of integrating various knowledge domains to solve the current problems facing most scientific disciplines (Wuchty, Jones, \& Uzzi, 2007, Jones, 2009). Thus from a process perspective, teams that can uncover and traverse a greater diversity of knowledge topics may have higher chances of creating high performing solutions as opposed to those that are narrowly focused (Uzzi et al., 2013).

Beyond encouraging effort and participation by individual members and ensuring that the appropriate diversity of contributions are provided and integrated, online collaborations are faced with the challenge of coordinating activity of the various members and ensuring that the inputs provided by the members are sufficient to effectively solve the problem at hand (Gibson \& Gibbs, 2006). The coordination of team activity has been a central concern for the literature on teams and has been shown to be an important factor in explaining team performance, especially in dispersed teams (Espinosa et al., 2007, Robert, Dennis, \& Ahuja, 2008, O'Leary \& Mortensen, 2010). This concern for coordination is even more severe in external collaborative settings as the traditional managerial and leadership hierarchy may not necessarily be immediately available (or even sought after) to guide the various activities of the individuals (O'Mahony \& Ferraro, 2007, 
Dahlander \& O'Mahony, 2011, Dahlander \& Frederiksen, 2012). Absent such explicit managerial oversight, a range of self-managing coordination practices may be needed to achieve collective task coherence and performance (O'Mahony \& Ferraro, 2007).

We turn next to describing more fully our hypotheses regarding the effects of incentives and social processes on member effort and interactions in these online settings.

\section{Incentives and Levels of Effort and Activity of Online Collaborators}

A cornerstone of economic theory is that workers respond to incentives (Lazear, 2000). Monetary incentives are the core foundation to induce high levels of effort in traditional firms (Prendergast, 1999, Lazear, 2000). The use of pricing and payments has also been the area of greatest emphasis within past research for strategically manipulating adoption and effort around a platform (Rochet \& Tirole, 2006, Parker \& Van Alstyne, 2012). At the same time, research on the role of worker incentives in innovation - often outside of research on platforms - has begun to illustrate a more nuanced effect around incentives in creative processes. For example, they may not always produce desired effects in creative problem-solving tasks (e.g., Manso, 2011). Further they can at times crowd out non-cash based motivations (e.g., Frey \& Jegen, 2001), which are especially important in the case of creative problem-solving work (e.g., Stephan, 1996).

The starting point in comprehending team production, in particular, within economics is that team production - while leveraging the complementarity of skills between workers-is subject to free riding (Alchian \& Demsetz, 1972, Lazear \& Shaw, 2007). When it is difficult for an employer to identify and reward the exact contribution made by each employee to the team output, employees working in a team will typically lack incentives to provide the optimal level of effort and work less than if they were working alone. This instance of the familiar 'moral hazard' problem - inducing agents to exert optimal amount of effort when effort cannot be observed and contracted for directly - has been the subject of a theoretical literature starting with Holmstrom (Holmstrom, 1982). These baseline models of teams and collaboration from economics and social psychology would each suggest online collaboration, particularly by anonymous workers outside of an employment relationship, should produce moral hazard (Holmstrom, 1982) and social loafing (Latane, Williams, \& Harkins, 1979). However, despite the risk of free riding, monetary incentives have been shown to be effective in settings where output measures are not the outcome of the inputs of a single individual but rather derive from the joint contribution of many individuals, when compared to alternative mechanisms such as incentive schemes that are not tied to output measures at all (Prendergast, 1999). Further, online platforms should also be particularly subject to selection effects; online team production could attract individuals of any number of characteristics and inclinations - including those having greater inclination to free riding (Kerr \& Bruun, 1983). Therefore, while as a baseline we should expect that cash incentives produce higher effort, their effectiveness is an empirical question and will depend upon possible offsetting effects of crowding out of alternative motivations, fundamental limits of team incentives, and the effects of worker selection processes. 
Hypothesis 1 (H1): Individuals' effort on an online platform will increase with cash incentives.

The presence of monetary incentives does not preclude the presence of alternative motivations. In fact, we often do observe online contexts where sustained efforts are observed in the absence of cash incentives, as were mentioned in the Introduction. This is in particular due to individuals responding diverse and heterogeneous sources of motivation (von Krogh et al., 2012, Algan et al., 2013, Benkler, 2013). The puzzle of motivations has been resolved by pointing to the many conspicuous non-monetary motivations experienced by those participating on collaborative peer production contexts. This includes direct, intrinsic motivations and any direct benefits from the use of any innovations by the contributor, him or herself (Lakhani \& Wolf, 2005). It also includes a range of what might be regarded as "socially-oriented" motivations, fed by the presence of other participants on the platform (Lakhani \& Wolf, 2005) These motivations include such things as an interest in gaining affiliation with the larger team as a community, or of accruing status or signaling one's expertise to the community (Butler et al., 2005, Lakhani \& Wolf, 2005, Lerner \& Tirole, 2005). Further, evidence suggests that rather than necessarily attracting loafers, a collaborative context may simply attract those who prefer collaboration and will work relatively diligently in these contexts (Boudreau, Lacetera, \& Lakhani, 2011). Online collaboration contexts, particularly those that provide immediate feedback about the quality of work, encompass the job characteristics most directly associated with internal motivation (i.e., variety of content, autonomy over how work is conducted, and knowledge of results; (Hackman \& Oldham, 1976) which are not dependent on the presence of cash incentives to elicit sustained effort.

Hypothesis 2 (H2): Individuals will exert effort and make contributions on an online platform even in the absence of cash incentives.

\section{Norms, Reciprocity, and Conditional Cooperation}

Research in economics suggests that contributions to public goods are difficult to explain by a narrow self-interest hypothesis (Fischbacher, Gächter, \& Fehr, 2001). Rather, recent theories focus on "conditional cooperation" in which people are assumed to be more willing to contribute when others contribute (Axelrod \& Dion, 1988, Frey \& Meier, 2004). This is consistent with work in social psychology on conformity, social norms (Bettenhausen \& Murnighan, 1985, Messick, 1999), guilt aversion (Chen \& Lim, 2013), and reciprocity (Rabin, 1993) which observe that collaboration and other pro-group behaviors often develop in feedback loops leading to self-fueling spirals (Lindsley, Brass, \& Thomas, 1995). These explanations depart from alternative explanations based on altruism, in which case helping behavior should decrease when it is perceived that help is supplied by others (Clotfelter, 1997). In particular, the theory of conditional cooperation predicts higher contribution rates when information is provided about other's contributions. More specifically, individuals may underestimate others' tendencies to contribute in the absence of information, and thus reduce their own contributions, but in response to evidence of others' contributing to a greater degree than expected, increase their own contributions accordingly (Frey \& Meier, 2004). 
A remarkable feature of online collaborative platforms in particular is the extent to which collaboration emerges from sophisticated team processes that evolve organically (Murphy, 2004), rather than direct architecting, governance or "ordering" by platform owners or "community managers" (Boudreau and Hagiu, 2009). This process has been referred to as "emergent interdependence" in research on more traditional teams (Wageman \& Gordon, 2005, Caruso \& Woolley, 2008), where individuals have some level of autonomy in influencing the intensity of interaction, as is very much the case in voluntaristic at-will collaborations on permeable online platforms. Whether interdependent activities and informal governance appear should then necessarily depend upon the degree to which behaviors and even ideas are observable and shared across group members (Cramton, 2001, Cramton \& Hinds, 2005). Therefore, individuals' engagement in collaborative effort-where it occurs at all-should generally intensify with time and growing number of interactions. This leads to the hypothesis that team engagement will influence the collaboration trajectory and assert a large impact on team participation and team effort relative to other sources of influence, i.e., cash incentives.

Hypothesis 3 (H3): Individuals' collaboration on an online platform will increase with the presence and increased effort of other participants, independent of cash incentives.

\section{Diversity of Information Shared, Temporal Coordination, and Performance}

Many online platforms are formed for the purpose of amassing a diverse array of independent or even mix-and-matchable contributions, such as mobile software applications on an apps market platform or product reviews on an opinions platforms (Boudreau, 2012). However, other online platform contexts are oriented to building solutions to problems in which contributions, knowledge and expertise of multiple parties is to be integrated and combined, as in models of collaborative communities and peer production (Y. Benkler, 2006, Haythornthwaite, 2009, Yochai Benkler, 2013). We posit that the synergistic gains to be obtained through true team emergent interdependence and collaboration online will be a strong predictor of solution quality. Here we draw a distinction between the exertion of effort, and the qualitative transformation to ongoing collaborative performance in the sense of effort involving collaboration with other contributors working on a platform. Thus, here we focus on the divide between whether individuals continue to work in parallel in mostly independent work (Hackman, 2011) or instead begin to interact and gradually structure collaborative and interdependent activities, and the quality of work those collaborations produce. In examining this in online groups, we focus on two key hallmarks of emergent interdependence: (1) the amount and diversity of information shared (Crawford and Haaland, 1972; Mesmer-Magnus \& DeChurch, 2009), and (2) the temporal coordination of communication and activity while conducting work (Thompson, 1967; Wageman, 1995)

The preponderance of the evidence available in the extant literature on collaboration

suggests that higher levels of emergent interdependence will lead to higher quality solutions to complex, multi-faceted problems (Wuchty, Jones, \& Uzzi, 2007, Gardner, 2012, Uzzi et al., 2013), even despite the loss of divergence in ideas that may occur as a result of interaction 
(Paulus, 2000) so long as the team shares a diverse range of information. One of the primary reasons to deploy teams to solve problems is the ability to solicit and integrate a diverse range of knowledge inputs into a problem solution (Reagans \& Zuckerman, 2001, Reagans, Zuckerman, \& McEvily, 2004, Gibson \& Gibbs, 2006, Pieterse, van Knippenberg, \& van Dierendonck, 2012, Shin et al., 2012). Ample evidence has documented a strong correlation between access to information-rich networks, and superior work performance (Ancona \& Caldwell, 1992, Burt, 1992, Reagans \& Zuckerman, 2001, Zaheer \& Bell, 2005, Aral, Brynjolfsson, \& Van Alstyne, 2012). Network structure is often used as a proxy for information flow because the structure of information flow can be measured more easily than the content of the actual information flow (Burt, 2008). Unfortunately, the vast majority of empirical work on networks and information advantage is "content agnostic" (Hansen, 1999). However, network positions may not adequately capture information flow as information exchange may occur strategically, for example, when individuals do not share all available information (Aral \& Van Alstyne, 2011). Consequently, there has been a call to open the black box that uses characteristics of network nodes as a proxy for information content and rather investigate the content itself (Burt, 2008, $\mathrm{Wu}, 2013$ ).

Organizational researchers have demonstrated that increasing teams' exposure to diverse information can enhance performance, especially on tasks requiring creativity (Bantel \& Jackson, 1989, McLeod, Lobel, \& Cox, 1996, Austin, 1997). Access to diverse information is also positively associated with individual performance. This inference has guided the way sociologists think about information flow in networks, and has motivated and informed empirical studies of innovation (Hargadon \& Sutton, 1997, Burt, 2004), academic output (Swedberg, 1991), team performance (Reagans \& Zuckerman, 2001, Lazer \& Friedman, 2007), the formation of industry structures (Walker, Kogut, \& Shan, 1997), the success of social movements (Centola \& Macy, 2007) and labor market outcomes (Montgomery, 1991). Tasks that require developing alternatives or creating plans of action are likely to benefit especially from access to knowledge and abilities that are diverse, because that diversity can lead to a greater quantity of ideas (Larson, 2010, Lewis \& Herndon, 2011) and also non-redundancy of ideas or perspectives in the group (Levine \& Moreland, 2004).

Hypothesis 4 (H4): Beyond initial contributions, information diversity characterizing team communications will be a strong predictor of team performance in an online platform (controlling for individual skill level and cash incentives).

The recombination and integration of inputs in online platforms, by their nature, should benefit from some higher level of coordinated activity across individual contributors (Malone \& Crowston, 1994, Thompson, 2003, Hackman \& Wageman, 2005). Thus coordination becomes another factor shaping productivity, apart from simply attracting capable contributors and motivating their efforts. For this reason, the history of online collaborative platforms, for example, stresses the use of enabling technologies and processes that simply reduce coordination costs. Particularly relevant here have been standardized tools, technical languages and interfaces, and enabling communications technologies (Preece \& Shneiderman, 2009). 
Despite the widespread availability of coordination tools, however, we know that coordinating efforts across widely distributed collaborators remains a major challenge (O'Leary \& Cummings, 2007). Many have lauded the availability of online tools for enabling the asynchronous coordination of efforts and have found that online teams can be even more effective than face-to-face teams (Sharda, Barr, \& McDonnell, 1988) while others have found that online teams could not outperform traditional teams (Warkentin, Sayeed, \& Hightower, 1997, McDonough, Kahnb, \& Barczaka, 2001), or that there are no differences between the two types of teams (Galegher \& Kraut, 1994, Burke \& Aytes, 1998, Burke \& Chidambaram, 1999).

One of the trickier aspects of coordinating groups online is managing the flow of communication. Human communication has been shown to have rich temporal structure (Barabasi, 2005). Although temporal patterns can be partially attributed to circadian and weekly rhythms (Malmgren et al., 2008), detailed analysis has shown that they have more fundamental origins (Karsai et al., 2012). In particular, human communication is known to be intrinsically bursty (Barabasi, 2005, Goh \& Barabási, 2008) and contain strong pairwise correlations of interaction times (Karsai et al., 2012). The temporal patterning of activities is an important aspect of team effectiveness in any environment (McGrath, 1991). Synchronous interaction is an orderly process wherein verbal and nonverbal cues help regulate the flow of conversation, enable turn taking, provide feedback, and convey subtle meanings. In lean, asynchronous communication environments, the communication of cues is hindered, feedback is delayed, and interruptions or long pauses in communication often occur (McGrath, 1991) which are difficult to interpret (Cramton, 2001). In an asynchronous discussion, typically many topics are active at the same time, with team members making contributions at different times, possibly on different topics. This pattern can increase information overload and may reduce the synergy of team members if there are no links among the responses. In addition, long time lapses between communication events can lead to discontinuous and seemingly disjointed discussions (Ocker et al., 1995, Montoya-Weiss, Massey, \& Song, 2001). This discussion suggests that a significant challenge facing online teams is coordinating the temporal patterns of group behavior (McGrath, 1991, Warkentin, Sayeed, \& Hightower, 1997) which has been shown to be critical to performance (Gersick, 1989, Montoya-Weiss, Massey, \& Song, 2001).

Consistent with existing research on temporal patterning in teams, we expect that in an online environment the temporal coordination of contributions to a shared product will be important to facilitating the collaboration necessary to a high level of performance in an otherwise sparse communication environment.

Hypothesis 5 (H5): The temporal coordination of activity within teams will be a strong predictor of their performance in an online platform. 


\section{RESEARCH DESIGN AND SETTING}

Investigating the drivers of emergent online collaborations is fraught with several empirical and methodological challenges. First, given the heterogeneity of projects that are pursued in online settings (from creating software, music, videos, to writing encyclopedia entries) it is important to ensure that the basis for comparison is limited to the factors impacting online collaborations and not so much driven by differences between projects. Second, since participation in many of these projects is non-random, important considerations like the effect of incentives on participation and individual ability and skills on project performance need to be factored into the study design. Also, participation and performance metrics across projects need to be directly comparable to ensure that appropriate inferences are drawn from the data. It is for these reasons we choose to implement the study in a field experimental setting that enabled us to obtain fine-grained measures and to employ randomized assignment.

The experiment was conducted over a ten day long online event held on the TopCoder open software innovation platform ${ }^{1}$, where participants developed computational algorithms to optimize the Space Flight Medical Kit, of the Integrated Medical Model Team at NASA. The TopCoder platform provides a ready-made infrastructure to host complex programming challenges and has a well developed ratings and skills assessment system that enables the identification of the ability of any competitor. Virtual workspaces were assigned to each team to enable messaging and communications and to enable code development. During the time of the competition we were then able to take detailed and objective measures of effort, communication, and performance.

We randomly assigned the 260 registered participants to groups of five to create 52 randomly-formed teams. Groups of four teams (20 individuals) were randomly assigned to virtual rooms to compete against one another. We randomized cash incentives across rooms. A total of 24 teams competed for a cash prize of $\$ 1,000$ and 28 rooms competed for $\$ 0$. (The precise split was determined by the size of our prize budget in relation to the number of participants signing up.) The awards in this case were team-based prize incentives, in that they would be shared across the five team members. For groups for which there was a cash prize, we anonymously polled the members of each team via a simple online questionnaire, immediately following the experiment and prior to the announcement of results. The questionnaire asked them to allocate a percentage of the $\$ 1,000$ to themselves and the other team members. Awards were based on the average allocation. Strong correlations between allocations and observable measures of effort and contributions suggest the mechanism captured meaningful variation and achieved our mean goal here of simply being "good enough" to provide a working allocation mechanism. It should also be emphasized that the particular institutional set-up implemented here involved not just collaboration and team work, but teams competing with other teams. This distinction was not relevant within the earlier theory-development. Members of the highest scoring team in the entire exercise (i.e., across all rooms) were also awarded a NASA Launch

${ }^{1}$ TopCoder is a platform for algorithm and software development contests with over 600, 000 registered members. A variety of public, private, and government organizations use 
Invitation where each of the five members of the highest-scoring team, if active, would be eligible to receive an invitation from NASA to view a NASA space shuttle launch (participants had to pay their own expenses to get to the Kennedy Space Center in Florida). Furthermore, all contestants who actively participated received a contest $\mathrm{T}$-shirt.

NASA and TopCoder collaborated with us in developing the appropriate test suite to generate an objective score for innovation problem solving performance which included generating 100,000 flight scenarios which were used in testing solutions. In addition, TopCoder worked with us to make various changes to their system and their website so that we could run controlled field experiments in their setting. For example, the platform was changed such that each team not only observed its own score, but could observe the scores of competing teams within their room on an ongoing basis (i.e., the highest score solution submitted up that that point).

The problem being solved is not just representative of a typical (highly-challenging) development problem; it is in fact a real computational-engineering problem whose solution is to be used by NASA. The selected problem required the development of a robust software algorithm, which would recommend the ideal components of the space medical kit, which is included in each space mission. As mass and volume are restricted in space flight, the medical kit has to be designed in a way so that as many expected and unexpected medical contingencies as possible can be met through the resources in the kit while in space. Otherwise the mission is aborted. The medical kit also has to be attuned to the characteristics of the space flight and crew. Hence, the challenge was to develop a software algorithm, based on mission characteristics that would minimize mass and volume of the medical kit and yet have the resources so that the likelihood of a medical evacuation is also minimized.

Participants' inclination toward initiating collaboration might be expected to be higher in this experimental collaboration setup than would be the case in a naturally occurring collaboration problem, for a number of reasons. First, we have solved the basic coordination problem of selecting prospective teammates, leaving just the decision of whether to collaborate or not to the participants. Second, participants have self-selected into the contest and have some inclination of the possibility of working in groups. Third, the platform, itself, is not a case of a newly-formed platform but rather an established online community of software and algorithm developers. So we are looking at the coalescence of groups of collaborators on a platform, rather than the genesis of a broader community. However, our experimental tournament was the first tournament on the TopCoder platform to involve teamwork. Prior to that point, all tournaments were designed as competitions between individuals.

The individuals who participated in this exercise were those who chose to respond to our open call to members of the platform. The participants were, to some extent, aware of the possibility of working in groups, but this was not the central message of our post. We stressed that this would be a competition to solve a challenging algorithmic design problem. The usual mode of interaction on this platform was in the form of individuals competing with one another to solve such problems. It was only in the course of the exercise that we randomly selected this 
subset to be randomly assigned to teams. Inasmuch as individuals self-selected to join this contest we should expect they might have already indicated some probability of being willing to participate in the exercise in general and in the possibility of joining a group to work, in particular. In this sense, we might expect the participation levels we observe in this context to perhaps be high in relation to what might be expected in a case in which an online platform attempts to encourage its members to coalesce into productive work groups under more typical operating conditions.

\section{Methods and Variables}

In this section we detail how we constructed the main variables used in our empirical analysis and the methods used for analysis. In particular, we outline the automated text analysis used to construct our measure of information diversity and the approach used to index the temporally correlated heterogeneous behavior of activity.

Dependent Variable - Effort. We measured individuals' effort through a postexperiment online survey in which we asked them to report the hours they spent working on the problem assignment. While this has some of the drawbacks associated with self reports, our analysis shows that the measure is highly correlated with the number of submission attempts made and submission quality..

Dependent Variable - Number of Communications. Participants interacted on the platform through a web-based interface screen, as in typical operation. This screen included a workspace where they could read the problem statement, perform algorithm development (i.e., in the form of software coding; a number of software languages were possible), and submit solutions for compilation. Further, individuals could communicate with other participants within their group via a bulletin board. That is, individuals could engage in general or directed communications to other group members by virtue of the content of their messages but communications were observable on a posting "board" or online forum visible to all group members (but not visible to other groups). Such a posting board was familiar to the platform as a general posting and discussion forum tool. Number of communications is indexed as the number of messages sent to the group message board.

Dependent Variable - Team Score. At the end of the competition, the last submission of each team (irrespective of which individual made the submission) undergoes final system testing to determine an objective performance score of the algorithm. The score is an objective measure of the quality of the algorithm that a team has developed. The score is computed as a function of the mass and volume of the medical kit (lower is better) and the number of evacuation scenarios that can be averted with the medical kit (higher is better). Team score is measured on the team level.

Process Variable - Information Diversity. To index the effects of information diversity on team performance, we perform automated content analysis of all messages sent within each team. We perform the usual preprocessing of eliminating stop words and stemming. Stop words are common words such as articles ("a", "an", "the") and prepositions (e.g., "from", "of", "to"). Stemming reduces words to their root; for example, "running" is recorded as its root, "run". 
Furthermore, we removed numbers from the text and restricted our text analysis to word stems of at least two characters in length. We then perform content analysis using latent Dirichlet allocation (LDA) to classify content into distinct topics using a Gibbs sampler. LDA is an advanced statistical technique that is widely used in information retrieval and machine learning. It is a generative probabilistic model that allows modeling the topics of a corpus of documents. ${ }^{2}$ Each topic consists of a vector of words that are statistically related to each other. For example,

Table 1 shows four sample topics from a LDA topic model of 100 topics for a dataset of 2,246 news feeds from the Associated Press. The topic "Agriculture" has words including farmers, food, drought, and corn. Similarly, the topic "Politics" includes words such as party, government, opposition, and elections.

Table 1. Four Sample Topics from a 100-Topic LDA Model of Associated Press News Feeds ${ }^{3}$

\begin{tabular}{llll}
\hline "Transportation" & "Agriculture" & "Politics" & "Business" \\
\hline bus & farmers & party & company \\
radio & farm & government & offer \\
officials & food & political & stock \\
driver & agriculture & opposition & billion \\
spokesman & tons & elections & share \\
greyhound & agricultural & minister & deal \\
drivers & drought & communist & inc \\
truck & production & leader & corp \\
stopped & corn & national & sale \\
bridge & prices & president & sell \\
\hline
\end{tabular}

LDA classifies topics in two distinct steps. In the first step, the entire corpus of all team messages is used to discover the entire distribution of topics. In the second step, each individual message is assigned probabilities for each topic. This gives for each message a distribution over topics, which are most likely to have generated that message. We use LDA to model 100 topics using the entire corpus of all 1,741 team messages (after preprocessing, 1,705 non-empty documents with 5,853 terms remain). The exact number of topics used for the LDA topic modeling matters little. We find almost identical results using a wide number of topics, ranging from 50 to 150 . We then compute information diversity for each team as the average cosine dissimilarity of the topic space of each team's messages. This is a common measure, which is widely adopted in information retrieval research to measure diversity of information. Specifically, we measure a team $i^{\prime}$ 's information diversity $D I$ through a normalized, squared sum

${ }^{2}$ Given a document corpus, LDA models each document $d$ as a finite mixture over an underlying set of topics, where each topic $t$ is characterized as a distribution over words. A posterior Dirichlet parameter $\mathrm{g}(\mathrm{d} ; \mathrm{t})$ can be associated with the document $d$ and the topic $t$ to indicate the strength of $t$ in $d$. For details of the algorithm, please refer to (Blei, $\mathrm{Ng}, \&$ Jordan, 2003).

${ }^{3}$ D. Harman (1992) Overview of the first text retrieval conference (TREC-1). In Proceedings of the First Text Retrieval Conference (TREC-1), 1-20. 
of the cosine distance between the topic vectors of each of $N$ messages $d_{j}$ sent within the team and the mean topic vector $M_{i}$ representing all messages sent within team $i$. The exact formula is:

$$
I D_{i}=\frac{\sum_{j=1}^{N}\left(1-\cos \left(d_{j}, M_{i}\right)\right)^{2}}{N}
$$

Teams that send messages of a rich and diverse set of topics have higher information diversity scores than teams that send messages of a more homogenous topic distribution. Similar measures of information diversity have been reported, most notably the one used by Aral and Van Alstyne (2011). Our measure differs from theirs by applying advanced LDA topic modeling techniques rather than support vector machines.

Process Variable - Burstiness of Team Activity. To index the coordination of communication and code submissions within the team we constructed a measure of the "burstiness" of team activity, as a means of capturing the degree to which team members concentrated their communication and work effort during relatively contained time periods versus spreading them out over time, leading to a more uniform distribution of wait times in between team activity. Specifically, we constructed a measure capturing the bursty nature of team activity based on the wait times (in minutes) between each team activity (either sending a message to other team members or making a code submission). For each team $t$ we compute a coefficient of variation measure $B$ (Goh \& Barabási, 2008), defined as the ratio of the standard deviation to the mean of wait times $\tau$ between team activities

$$
B \equiv \frac{\left(\sigma_{\tau} / m_{\tau}-1\right)}{\left(\sigma_{\tau} / m_{\tau}+1\right)}=\frac{\left(\sigma_{\tau}-m_{\tau}\right)}{\left(\sigma_{\tau}+m_{\tau}\right)} .
$$

This measure is meaningful when both the mean and the standard deviation of wait times $P(\tau)$ exist, which is always the case for real-world finite signals (Goh \& Barabási, 2008). $B$ has a value in the bounded range $(-1,1)$, and its magnitude correlates with the signal's burstiness: $B=$ 1 is the most bursty signal, $B=0$ is neutral, and $B=-1$ corresponds to a completely regular (periodic) signal. Thus, higher values of $B$ correspond to spiked patterns of high team activity, while lower values of $B$ correspond to more regular team activity. Since teams did not send the same number of messages, we compute a bootstrapped null model of $B$ scores using 1,000 random samples for different numbers of messages sent within a team (i.e., what is the expected distribution of wait times, and hence of $B$, for a team that sent $\mathrm{N}$ messages?). Based on these random null models, we then compute a z-score of $B$ for each team. Figure 1 gives an intuition for the measure using completely random and bootstrapped data. 
Figure 1. Difference Between Activity Patterns

a)

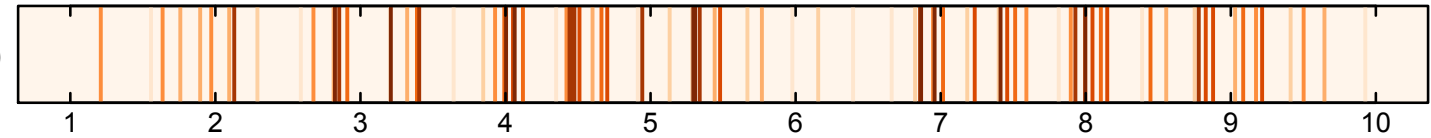

b)

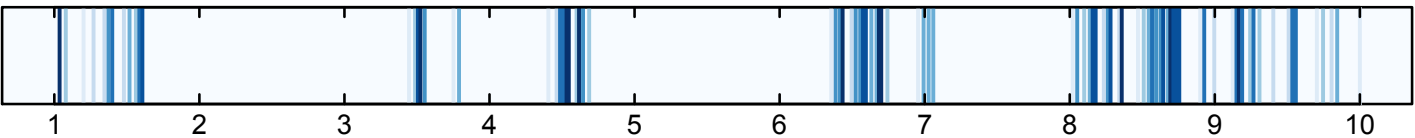

c)

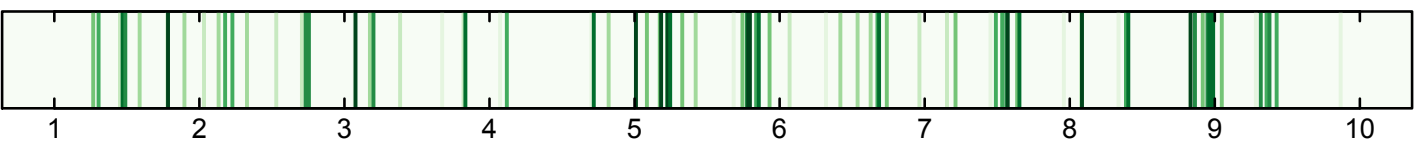

d)

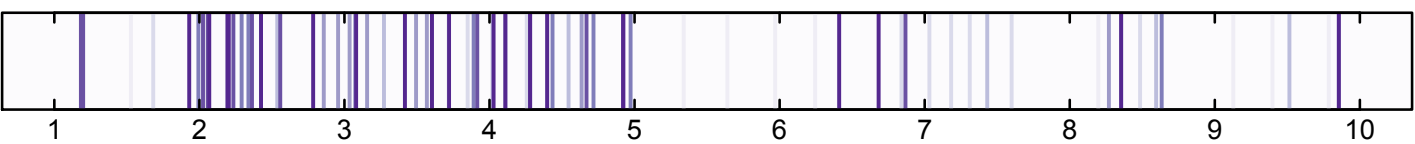

Note: Differences in activity patterns for teams with $\mathrm{N}=90$ communications with color-coded inter-communication times. Horizontal axis denotes time (day of competition), each vertical line corresponds to an individual communication event. The shorter the time between consecutive communications, the darker the color. a) Sequence of regular, Poisson distributed event times which assumes that at any given moment an event takes place with probability $q$. Note that the inter-event times are comparable to each other, long delays are virtually absent $(B=$ $-0.005)$; b) Sequence of events for a heavy-tailed (power-law) distribution. Note the very long delay times, followed by bursts of activity ( $B=0.228)$; c) Sequence of typical communication pattern for a well coordinated team, showing some longer wait times followed by bursts of activity, especially during the middle of the competition and towards the end $(B=0.208)$; d) Sequence of typical communication pattern for a poorly coordinated team with some bursts during the beginning of the competition followed by sparse and regular communication in the second half of the competition $(B=0.03)$.

Control Variable - Skill Rating. As an objective measure of the skill level of competitors, we use TopCoder's own skill rating based on historical performance of participants in TopCoder's own regular competitions (outside of the experiment). Because skill rating is a clear indication of both ability and experience on the TopCoder platform, we are interested in examining the effects of the group collaboration patterns observed above and beyond the effects of individual skills.

Control Variable - Collective Team Output. As an additional control measure, we use the count of the number of code submissions made by a team as a control for team effort. Prior research has shown that in tournaments allowing repeat entries, the number of submitted attempts is a strong predictor of performance (Wooten \& Ulrich, 2012).

Control Variable - Number of Time Zones. Research has shown that the dispersion of team members across time zones can affect the level of team coordination. For example, teams spanning multiple time zones often experience significant challenges coordinating schedules and deliverables (Massey, Montoya-Weiss, \& Hung, 2003, O'Leary \& Cummings, 2007, O'Leary \& Mortensen, 2010). To control for the effect of temporal dispersion in our teams, we control for the number of time zones represented in each team.

Control Variable - Number of Countries. Research has shown that compositional diversity with regard to team members' cultural backgrounds can affect team performance 
(Reagans, Zuckerman, \& McEvily, 2004, Gibson \& Gibbs, 2006, O’Leary \& Mortensen, 2010). To control for the effect of cultural diversity in our teams, we control for the number of different countries represented in each team.

The 260 competitors came from 50 different countries with more than $50 \%$ of the competitors coming from four countries: India (18\%), China (13\%), USA (12\%), and Russia (9\%). Tables 2 and 3 show the descriptive statistics for the main variables on the individual- and team-level, respectively.

Table 2. Descriptive Statistics for Main Variables on Individual-Level

\begin{tabular}{|c|c|c|c|c|c|c|c|c|c|c|c|c|}
\hline & Mean & SD & Min & Max & $(1)$ & $(2)$ & $(3)$ & $(4)$ & $(5)$ & $(6)$ & $(7)$ & $(8)$ \\
\hline HoursWorked ( 1 ) & 8.86 & 15.64 & 0.00 & 100.00 & & & & & & & & \\
\hline NumCommunications ( 2 ) & 3.18 & 10.59 & 0.00 & 116.00 & $0.44^{* * *}$ & & & & & & & \\
\hline Rating ( 3 ) & -0.04 & 0.86 & -1.88 & 4.32 & $0.18^{* *}$ & $0.22^{* * *}$ & & & & & & \\
\hline GroupCashIncentive ( 4 ) & 0.46 & 0.50 & 0.00 & 1.00 & $0.21 * * *$ & 0.02 & 0.10 & & & & & \\
\hline Number of active members, other $4(5)$ & 1.85 & 1.15 & 0.00 & 4.00 & $0.19^{* *}$ & $0.25^{* * *}$ & 0.00 & $0.26^{* * *}$ & & & & \\
\hline HoursWorked, Other $4(6)$ & 35.45 & 36.15 & 0.00 & 153.00 & $0.19^{* *}$ & $0.26^{* * *}$ & 0.08 & $0.37^{* * *}$ & $0.70^{* * *}$ & & & \\
\hline NumComms, Other 4 ( 7 ) & 12.71 & 28.38 & 0.00 & 221.00 & $0.22^{* * *}$ & $0.40^{* * *}$ & 0.12 & 0.03 & $0.49^{* * *}$ & $0.57 * * *$ & & \\
\hline NumTimeZones, Other $4(8)$ & 3.26 & 0.75 & 1.00 & 4.00 & 0.05 & -0.01 & -0.07 & $0.16^{* *}$ & $0.14^{*}$ & 0.12 & 0.03 & \\
\hline NumCountries, Other $4(9)$ & 3.49 & 0.65 & 1.00 & 4.00 & -0.02 & -0.10 & -0.06 & 0.02 & -0.01 & -0.05 & -0.09 & $0.52^{* * *}$ \\
\hline
\end{tabular}

Table 3. Descriptive Statistics for Main Variables on Team-Level

\begin{tabular}{|c|c|c|c|c|c|c|c|c|c|c|c|c|c|}
\hline & Mean & SD & Min & $\operatorname{Max}$ & $(1)$ & $(2)$ & $(3)$ & $(4)$ & $(5)$ & $(6)$ & $(7)$ & $(8)$ & $(9)$ \\
\hline GroupCashIncentive ( 1 ) & 0.46 & 0.50 & 0.00 & 1.00 & & & & & & & & & \\
\hline Team HoursWorked ( 2 ) & 44.32 & 42.41 & 0.00 & 153.00 & $0.40^{* *}$ & & & & & & & & \\
\hline Team NumSubmissions ( 3 ) & 12.02 & 15.05 & 0.00 & 76.00 & $0.34^{*}$ & $0.73^{* * *}$ & & & & & & & \\
\hline Team NumCommunications ( 4 ) & 15.88 & 34.26 & 0.00 & 222.00 & 0.03 & $0.60^{* * *}$ & $0.55^{* * *}$ & & & & & & \\
\hline Team MeanRating ( 5 ) & -0.04 & 0.36 & -0.78 & 0.66 & 0.24 & $0.32 *$ & $0.42^{* *}$ & $0.40^{* *}$ & & & & & \\
\hline Team Score $(6)$ & 4170.53 & 3351.06 & 0.00 & 8952.79 & 0.27 & $0.69^{* * *}$ & $0.73^{* * *}$ & $0.45^{* * *}$ & $0.42^{* *}$ & & & & \\
\hline Team NumTimeZones ( 7 ) & 3.85 & 0.96 & 2.00 & 5.00 & 0.19 & 0.12 & 0.25 & 0.00 & -0.08 & 0.06 & & & \\
\hline Team NumCountries ( 8 ) & 4.19 & 0.84 & 2.00 & 5.00 & 0.02 & -0.09 & -0.04 & -0.15 & 0.03 & -0.05 & $0.52^{* * *}$ & & \\
\hline Information Diversity ( 9 ) & 0.03 & 0.04 & 0.00 & 0.17 & 0.11 & $0.56^{* * *}$ & $0.63^{* * *}$ & $0.56^{* * *}$ & $0.31^{*}$ & $0.62^{* * *}$ & 0.10 & -0.05 & \\
\hline Burstiness (z-score) ( 10$)$ & 1.99 & 2.21 & -1.89 & 8.46 & 0.12 & $0.63^{* * *}$ & $0.65^{* * *}$ & $0.75^{* * *}$ & $0.44^{* *}$ & $0.67 * * *$ & -0.03 & -0.25 & $0.74^{* * *}$ \\
\hline
\end{tabular}




\section{RESULTS}

\section{The Impact of Cash Incentives}

We begin by examining the effects of the presence and absence of monetary incentives on individuals' behaviors.

Figure 2 shows the distribution of HoursWorked and NumCommunications with and without cash incentives. It shows that cash incentives substantially statistically increased the likelihood of participating (HoursWorked $>0$ hours) from $39 \%$ to $54 \%$, while also quite resolutely shifting the distribution of effort rightward (difference significant at $p<.05$ ). This explicit depiction shows no such dramatic effect on communications (although it is possible to see the small and insignificant effect with a slightly higher but statistically insignificant share of individuals choosing to make at least one communication).

Figure 2. Distribution of Effort (left) and Number of Communications (right) by Cash Incentive Treatment

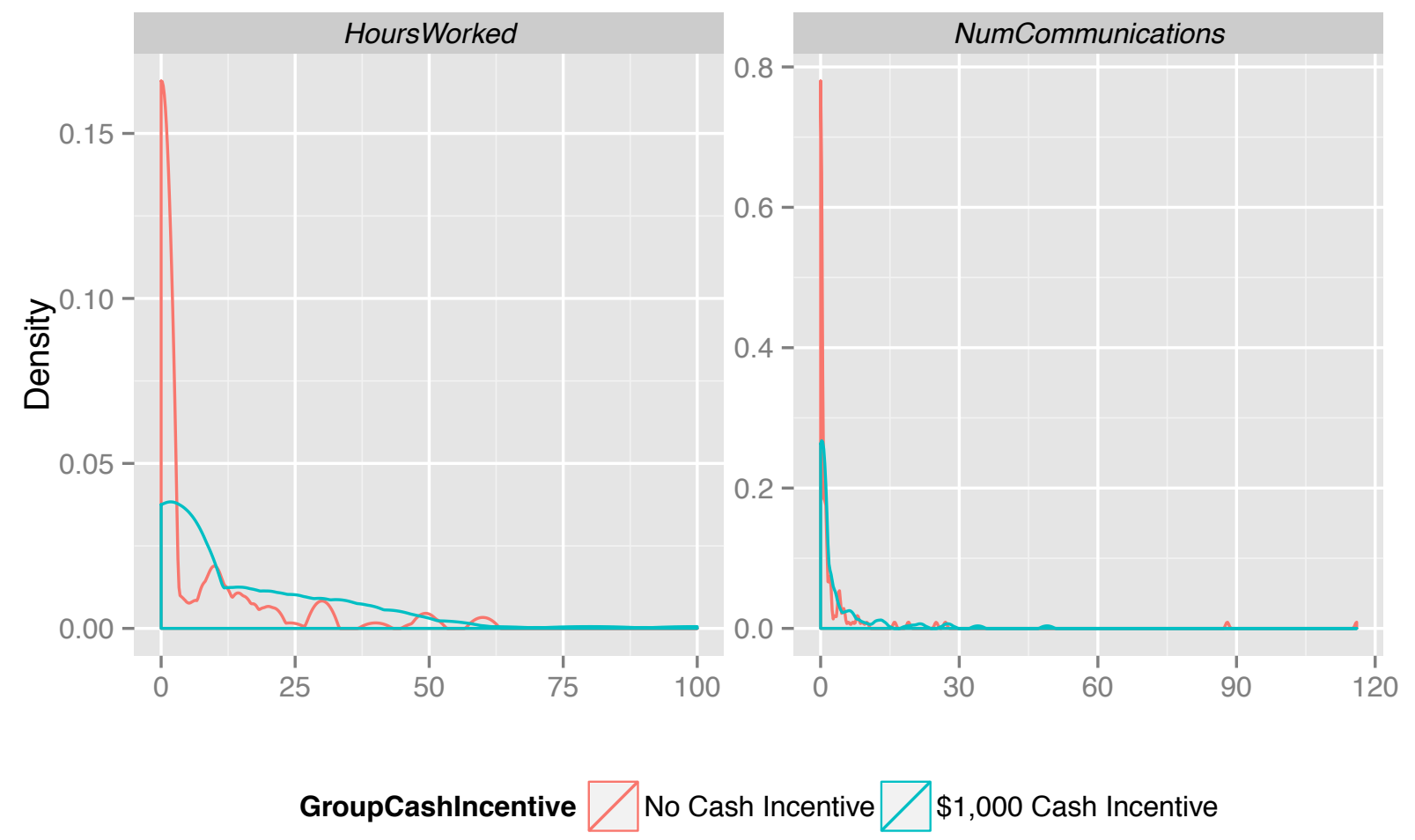

We report OLS results with clustered standard errors (using the team-of-five as the grouping level). In

Table 4, Model (1) beings by simply regressing our measure of effort, HoursWorked, on the CashIncentive dummy with a constant. The estimated constant is 5.78 hours $(p<.001)-$ indicating that, on average, even in the absence of monetary incentives individuals' exerted considerable effort (roughly a half hour per day of the competition). This is evidence of ample non-monetary motivations, which supports Hypothesis 2. The estimated coefficient on 
CashIncentive is 6.68 hours $(p<.001)$, meaning that the presence of a cash incentive more than doubled the average effort exerted, supporting Hypothesis 1.

We then turn to analogous regressions in which the number of communications becomes the dependent variable, replacing the hours worked (Model 2) - thus providing us with a more direct sense of interactive activity among team members. Consistent with the earlier results, individuals interact and communicate significantly, even in the absence of cash incentives. This is shown by the constant term of $3.01(p<.1)$, which is the average number of communications per individual in the absence of cash incentives. However, in stark contrast to the effect on effort, the average number of communications does not statistically differ in teams given the cash incentive. The coefficient is positive ( $\beta=.37$ ) but not statistically significant.

Table 4. OLS Regressions of Individual Activity on Cash Incentive and Team Complementarity

\begin{tabular}{lccc}
\hline \hline Dependent variable: & HoursWorked & NumCommunications \\
\cline { 2 - 2 } & $(1)$ & $(2)$ \\
\hline GroupCashIncentive & $6.676^{* * *}$ & 0.368 \\
Constant & $(2.233)$ & $(1.829)$ \\
& $5.782^{* * *}$ & $3.007^{*}$ \\
& $(1.189)$ & $(1.586)$ \\
\hline Observations & 260 & 260 \\
Adjusted $\mathrm{R}^{2}$ & $0.042^{* * *}$ & -0.004 \\
F Statistic $(\mathrm{df}=1 ; 258)$ & $12.283^{*}$ & 0.078 \\
\hline \hline
\end{tabular}

Note:

${ }^{*} \mathrm{p}<0.1 ;{ }^{* *} \mathrm{p}<0.05 ;{ }^{* * *} \mathrm{p}<0.01$

Clustered robust standard errors in parentheses.

\section{The Impact of Team Complementarity}

We continue by investigating effects of team complementarity to answer the question if individuals' collaboration on an online platform will increase with the presence and increased effort of other participants (i.e., conditional cooperation). We start with a binary measure of individual activity: is an individual active (HoursWorked $>0$ ) or not. We present our results of regression analyses of team complementarity in Error! Reference source not found. All models use an individual's skill rating as a control, which is statistically significant and positive in all models. All models also include counts of the number of time zones and the number of countries represented in each team as control measures for compositional team diversity. Models 1 and 2 are logistic regressions using a dichotomous indicator of individual's status as an active participant as dependent variable. Model 1 introduces the number of active team members as our main explanatory variable. We find a statistically significant and positive coefficient of .373 (p $<$ .05 ). We find that an individual's likelihood of being active increases by about $41 \%$ with each additional active teammate. Model 2 introduces GroupCashIncentive as an additional 
explanatory variable, which is not statistically significant. This provides initial support for Hypothesis 3.

Table 5. Individual Likelihood to be Active, Effort and Communication

\begin{tabular}{|c|c|c|c|c|c|}
\hline \multirow[t]{3}{*}{ Dependent variable: } & \multicolumn{2}{|c|}{ Individual Likelihood to be Active } & \multicolumn{2}{|c|}{ Hours Worked } & \multirow{3}{*}{$\begin{array}{c}\text { NumCommunications } \\
\text { OLS } \\
(5) \\
\end{array}$} \\
\hline & \multicolumn{2}{|c|}{ logistic } & \multicolumn{2}{|c|}{$O L S$} & \\
\hline & $(1)$ & $(2)$ & $(3)$ & $(4)$ & \\
\hline Number of active members, Other 4 & $\begin{array}{l}0.343^{* *} \\
(0.164)\end{array}$ & $\begin{array}{c}0.312^{*} \\
(0.180)\end{array}$ & & & \\
\hline GroupCashIncentive & & $\begin{array}{c}0.294 \\
(0.269)\end{array}$ & $\begin{array}{l}4.601^{* *} \\
(2.208)\end{array}$ & $\begin{array}{l}5.999^{* * *} \\
(2.243)\end{array}$ & $\begin{array}{c}-0.670 \\
(1.359)\end{array}$ \\
\hline Hours Worked, Other 4 & & & $\begin{array}{c}0.052 \\
(0.037)\end{array}$ & $\begin{array}{c}-0.004 \\
(0.039)\end{array}$ & $\begin{array}{c}0.016 \\
(0.026)\end{array}$ \\
\hline NumComms, Other 4 & & & & $\begin{array}{l}0.111^{* * *} \\
(0.023)\end{array}$ & $\begin{array}{l}0.126^{* * *} \\
(0.015)\end{array}$ \\
\hline \multicolumn{6}{|l|}{ Controls } \\
\hline Skill Rating & $\begin{array}{l}0.829^{* * *} \\
(0.189)\end{array}$ & $\begin{array}{l}0.816^{* * *} \\
(0.189)\end{array}$ & $\begin{array}{l}2.875^{* * *} \\
(0.925)\end{array}$ & $\begin{array}{l}2.556^{* * *} \\
(0.870)\end{array}$ & $\begin{array}{c}2.119^{* *} \\
(0.845)\end{array}$ \\
\hline NumTimeZones, Other 4 & $\begin{array}{c}0.357^{*} \\
(0.190)\end{array}$ & $\begin{array}{c}0.326 \\
(0.201)\end{array}$ & $\begin{array}{c}0.956 \\
(1.315)\end{array}$ & $\begin{array}{c}0.835 \\
(1.286)\end{array}$ & $\begin{array}{c}0.411 \\
(0.568)\end{array}$ \\
\hline NumCountries, Other 4 & $\begin{array}{c}-0.285 \\
(0.248)\end{array}$ & $\begin{array}{c}-0.275 \\
(0.255)\end{array}$ & $\begin{array}{c}-0.810 \\
(1.646)\end{array}$ & $\begin{array}{c}-0.496 \\
(1.692)\end{array}$ & $\begin{array}{c}-1.143 \\
(0.921)\end{array}$ \\
\hline Constant & $\begin{array}{c}-0.936 \\
(0.958) \\
\end{array}$ & $\begin{array}{c}-0.950 \\
(0.961) \\
\end{array}$ & $\begin{array}{c}4.709 \\
(6.598) \\
\end{array}$ & $\begin{array}{c}3.914 \\
(6.973) \\
\end{array}$ & $\begin{array}{c}4.033 \\
(3.740) \\
\end{array}$ \\
\hline Observations & 260 & 260 & 260 & 260 & 260 \\
\hline Adjusted $\mathrm{R}^{2}$ & & & 0.068 & 0.091 & 0.172 \\
\hline Log Likelihood & -160.471 & -159.919 & & & \\
\hline F Statistic & & & $4.804^{* * *}$ & $5.309^{* * *}$ & $9.993^{* * *}$ \\
\hline
\end{tabular}

We find no evidence of direct complementarity across workers. As reported in Model 3, an individual worker's effort does not increase significantly in the presence of high effort of other individuals in one's own team. Introducing the number of communications of the four other members of a team, Model 4, shows the complementarity is not between effort choices per $s e$; rather others' communications positively shape individuals' effort choices. The number of communications of the four other members shapes the effect, and the coefficient on the four others' effort goes to zero. As theorized previously, this demonstrates the importance of participants' ability to observe the effort levels of others; when effort occurs privately, in absence of communication, it is not observable to non co-located team members. It should also be noted that there is a strong association between effort and communications choices: individuals who worked more tended to also communicate more - however, for the most part, this relationship would appear to be orthogonal to the provision of cash incentives. This is particularly strong evidence that while cash incentives are a potent motivator of effort, they do not encourage interactions or collaboration as such in this case, further supporting Hypothesis 3.

Given the earlier finding of complementarities impacting effort, Model 5 then introduces the number of communications and hours worked of the other four individuals. Consistent with the earlier patterns, the complementarity is with observable communications of others rather than unobservable effort within the same team. This is not surprising, as one should expect that 
communications tend to elicit reciprocating communications. It is not possible to statistically infer the direction of causality but it stands to reason the effect works both ways with reciprocating interactions and communications. ${ }^{4}$

It remains plausible from these results that individuals who work harder simply communicate more, and it is the communications that stimulate effort (rather than a direct complementarity of communications along with a complementarity in effort). In principle, it should be difficult to discern these fine distinctions, given both communications and hours worked are endogenous and presumably chosen simultaneously by individuals as they interact with the team. However, introducing HoursWorked into the regression has negligible effect on the point estimates of coefficients on other's posts. This is consistent with the interpretation of a direct complementarity acting across communications, along with communications stimulating effort (as earlier established).

\section{The Impact of Information Diversity and Temporal Coordination}

Having established basic evidence of team complementarity, we continue by investigating more closely the type of information shared within a team, i.e., information diversity, and the timing of those messages. For this analysis, we shift to the team level as our unit of analysis and we use Team Score as our dependent variable. We report OLS results with robust standard errors in

Table 6. It is important to note that with this shift in level of analysis, the number of observations available to study consequently decreases from 260 to 52 . We investigate if team performance on an online platform is driven by the information diversity characterizing team communications first. Model (1) begins by simply regressing our outcome measure, Team Score, on a set of control measures, including GroupCashIncentive, Rating, collective team output ${ }^{5}$ number of team messages (NumCommunications), number of time zones, and number of countries represented in each team. The average team score achieved by teams is 2,360 . Of the control measures, only the measure of number of code submissions is statistically significant. This is consistent with prior research on tournaments allowing repeat entries (Wooten \& Ulrich, 2012) and adds to the results presented above on effort showing that increased effort does indeed lead to higher team performance. Each additional code submission increases the final team score by 145 points.

Table 6. OLS Regression of Team Score on Information Diversity and Burstiness at the Team Level

4 The count of others' communications might reflect an individual's responses to team members, the team members' responses to the individual, or more likely both.

${ }^{5}$ Alternative measures of team effort such as sum of hours works, or the use of both measures simultaneously do not substantively change our results. 


\begin{tabular}{|c|c|c|c|c|}
\hline \multirow[t]{2}{*}{ Dependent variable: } & \multicolumn{4}{|c|}{ Team Score } \\
\hline & (1) & $(2)$ & $(3)$ & $(4)$ \\
\hline $\begin{array}{l}\text { Information Diversity } \\
\text { (standardized) }\end{array}$ & & $\begin{array}{l}904.755^{* *} \\
(458.167)\end{array}$ & & $\begin{array}{c}396.674 \\
(484.093)\end{array}$ \\
\hline $\begin{array}{l}\text { Burstiness } \\
\quad(z \text {-score })\end{array}$ & & & $\begin{array}{l}698.388^{* * *} \\
(235.807)\end{array}$ & $\begin{array}{l}582.794^{* *} \\
(271.207)\end{array}$ \\
\hline Controls & & & & \\
\hline$\overline{\text { GroupCashIncentive }}$ & $\begin{array}{c}212.640 \\
(677.772)\end{array}$ & $\begin{array}{c}333.495 \\
(676.218)\end{array}$ & $\begin{array}{c}311.864 \\
(625.084)\end{array}$ & $\begin{array}{c}348.427 \\
(642.663)\end{array}$ \\
\hline Rating & $\begin{array}{r}855.888 \\
(1,028.078)\end{array}$ & $\begin{array}{c}881.030 \\
(976.395)\end{array}$ & $\begin{array}{c}386.535 \\
(940.228)\end{array}$ & $\begin{array}{c}475.243 \\
(969.289)\end{array}$ \\
\hline Collective Team Output & $\begin{array}{l}156.822^{* * *} \\
(51.924)\end{array}$ & $\begin{array}{l}126.224^{* *} \\
(52.145)\end{array}$ & $\begin{array}{l}121.476^{* *} \\
(52.487)\end{array}$ & $\begin{array}{l}113.912^{* *} \\
(53.904)\end{array}$ \\
\hline NumCommunications & $\begin{array}{c}3.370 \\
(7.318)\end{array}$ & $\begin{array}{c}-4.437 \\
(7.239)\end{array}$ & $\begin{array}{c}-18.821^{* *} \\
(9.438)\end{array}$ & $\begin{array}{r}-18.571^{*} \\
(10.330)\end{array}$ \\
\hline NumTimeZones & $\begin{array}{c}-502.527 \\
(442.538)\end{array}$ & $\begin{array}{c}-468.066 \\
(404.488)\end{array}$ & $\begin{array}{c}-472.959 \\
(396.102)\end{array}$ & $\begin{array}{l}-462.744 \\
(388.603)\end{array}$ \\
\hline NumCountries & $\begin{array}{c}222.522 \\
(418.412)\end{array}$ & $\begin{array}{c}185.146 \\
(407.859)\end{array}$ & $\begin{array}{c}507.027 \\
(365.631)\end{array}$ & $\begin{array}{c}443.550 \\
(372.557)\end{array}$ \\
\hline Constant & $\begin{array}{r}3,164.884^{*} \\
(1,775.792) \\
\end{array}$ & $\begin{array}{c}3,625.930^{* *} \\
(1,791.133) \\
\end{array}$ & $\begin{array}{c}1,181.515 \\
(1,428.084) \\
\end{array}$ & $\begin{array}{c}1,711.929 \\
(1,633.520) \\
\end{array}$ \\
\hline Observations & 52 & 52 & 52 & 52 \\
\hline Adjusted $\mathrm{R}^{2}$ & 0.510 & 0.544 & 0.578 & 0.575 \\
\hline F Statistic & $9.855^{* * *}$ & $9.677^{* * *}$ & $10.996^{* * *}$ & $9.630^{* * *}$ \\
\hline
\end{tabular}

Model (2) introduces our measure of Information Diversity, which is statistically significant $(p<.05)$ with a positive coefficient: a one standard deviation increase in Information Diversity corresponds to an increase in team score by 920 points. It is important to note that the regression controls for the total number of messages sent within a team. This supports H4. ${ }^{6}$

We continue by investigating temporal coordination of communication within teams as a predictor of team performance. Model (3) regresses our measure of Burstiness on team score, again controlling for total number of messages sent within a team. Burstiness is statistically significant $(p<.01)$ and positive, with a one standard deviation increase in Burstiness corresponding to 1,090 points increase in team score. Finally, Model (4) introduces both measures simultaneously. The measure of Information Diversity is not statistically significant while Burstiness is statistically significant with a coefficient of comparable size as in the previous model $(\beta=947)$. In this case we find group coordination in communication (the timing aspect of messages), keeping the total number of messages and the information diversity of those messages constant, is the main determinant of group effectiveness, further supporting H5.

${ }^{6}$ We find no relationship between information diversity and team diversity such as number of represented countries in a team. 


\section{DISCUSSION AND CONCLUSION}

In this paper, we explored factors determining the emergence of collaboration in online teams. Our approach considers (1) a perspective emphasizing the role of incentives in catalyzing effective work by teams; and (2) a perspective emphasizing more subtle social processes and interactions among team members to catalyze effective work by teams.

Regarding the role that incentives play in the emergence of collaboration, we find considerable heterogeneity in individual's willingness to participate and to exert effort both with and without cash incentives. We find that cash incentives had a sharp effect on online workers' continuous choice of level of effort. Thus, despite the range of possible limitations of team-based cash incentives, clearly cash generated a sharp difference in average levels of activity. A corollary to the doubling of effort in response to cash incentives is that half the level of effort was still achieved with no cash incentives at all. Further, the application of cash incentives also did not affect the probability of an individual taking the discrete decision to communicate - at all. This is consistent with a growing body of work on participation and motivations of workers in collaborative online contexts that points to the importance of non-cash based incentives and motivations(e.g., Roberts, Hann, \& Slaughter, 2006). Although cash incentives stimulated a significant boost of effort per se, it is equally notable that they did not transform the nature of the work process or affect the level of collaboration, as proxied by team communications. The effect of cash incentives appears to be focused on the continuous decision of the level of effort to exert in this context.

Regarding socially emergent processes, we find a number of patterns consistent with a highly socialized process of emergent interdependence. At a basic yet striking level, we observe that the likelihood that an individual chooses to participate depended on whether teammates were themselves active. We find that an individual's likelihood of being active increases by about $41 \%$ with each additional active teammate. Moreover, communications among teammates begot more communications and communications among teammates also stimulated greater continuous levels of effort expenditures. An individual worked about seven minutes more with each additional communication sent by a team member. This suggests that it is important for communication design to provide observable signals about the fact that team members are actively working on the task at hand rather than free riding and slacking. Hence, providing adequate communications channels to make the efforts of others visible is important in the design of systems for online work as it helps to confirm that others are actively contributing.

Consistent with the existence of these social processes and their contribution to team performance in this context, we find problem-solving performance levels to be correlated with the range and diversity of information and topics exchanged in communications and the extent to which communications appear to be closely-spaced. This pattern of "bunched" communications is consistent with active interactions.

The importance of these results regarding social processes underlines a fundamental role that teams are to play in this context—one of eliciting diverse contributions and ideas (Crawford \& Haaland, 1972, Wuchty, Jones, \& Uzzi, 2007, Uzzi et al., 2013). It appears that "effort" per se 
is not sufficient in delivering the transformation in work mode to fully capture this essential driver of team productivity in this context. Apart from eliciting these diverse contributions, there is an equally important challenge of harnessing, channeling, and coordinating these contributions. While the virtuous cycles documented here do not suggest these things can be understood as entirely independent mechanisms and processes, we see separate indication of the role of coordinated interactions in the correlation between team performance and the extent to which team members concentrated their communication and work effort during relatively contained time periods. This pattern of "bunched" team activity is consistent with active and deliberate interactions and "temporal coordination" (Montoya-Weiss, Massey, \& Song, 2001).

Important to emphasize in these results is the question of complementaries in behavior (as distinct from possible complementarities in knowledge). The complementarities across actors in a team were driven by reactions to communications in particular; it is not that workers raise their efforts in response to others' work and effort, per se, but rather that individuals raise their work efforts in relation to the level of communications of teammates. This again underlines the importance of the social interactive processes. At the same time, individuals' communications increase in response to teammates' communications. Thus, apart from communication leading to a qualitative transformation of work to involve more interactions, the patterns are consistent with the virtuous circle of interactions themselves driving the level of effort. These patterns of reciprocating complementarities are consistent with the importance of setting productive social interactions and dynamics into motion in order to catalyze collaboration (Bettenhausen \& Murnighan, 1985, Ginnett, 1993, Ericksen \& Dyer, 2004), even in this rather weak social context.

These patterns distinguish groups in which there is simply high effort from those in which there is true interdependence and emergent collaboration (Wageman \& Gordon, 2005, Caruso \& Woolley, 2008, Hackman, 2011) with the latter being the locus of true innovation in face-to-face contexts. In drawing this bright distinction and showing its implications, these findings might also be judged as shedding further light on how perspectives on incentives, predominant in economics, and perspectives on social processes and interactions, predominant in research on organizational behavior and teams, might be better understood.

While our findings contribute to answering a number of questions about the initiation of collaboration in online environments, a number of questions for future research are suggested as well. Though participants were informed that they might be working in teams in this contest, most were not accustomed to working in this manner in a contest of this type. Thus we do not know if participants were self-selected for their level of interest in collaboration, and the degree to which this influences our findings. Future research should examine how the behavior of those who self-select into team collaboration differs from those who prefer to work individually to gauge how this would change the factors that are most influential to performance. In addition, while participants who were assigned to our "incentive" condition were eligible for a prize, none of our participants were directly paid for their effort. Thus the degree to which our findings 
would generalized to a setting in which salaried employees are paid for their time to work in an online platform is a matter that should also be examined in future research.

The questions our study answers represent an important extension of the literature on online collaboration and team performance in a number of ways. First and foremost, the unique nature of this field experimental setting allows us to make stronger causal claims about the effects of cash incentives and collaboration on performance than has been possible in prior studies. In particular, the finding that cash incentives do drive effort, yet do nothing to stimulate collaboration provides an important contribution to existing literature. Second, while the effects of incentives, information diversity, and temporal coordination have been studied independently in prior work, our ability to examine their independent and combined effects allows us to separate the factors affecting effort versus those that affect the quality of collaboration, and their relative contributions to performance. Third, the completeness of our observed data on the teams' collaboration as well as the high fidelity of our metrics of individual skills and team performance allows us to examine and control for important variables that are often treated as sources of error in more traditional field studies of team collaboration. Thus we are able to more precisely specify the effects of the team process variables and underscore their importance as a design principle for improving collaboration in online environments.

Alchian, A. A. and H. Demsetz

\section{REFERENCES}

1972 "Production, information costs, and economic organization." American Economic Review, 62: 777-795.

Algan, Y., Y. Benkler, M. F. Morell, and J. Hergueux

2013 "Cooperation in a Peer Production - Economy Experimental Evidence from Wikipedia." Workshop on Information Systems and Economics, Milan, Italy: 1-31.

Ancona, D. G. and D. F. Caldwell

1992 "Bridging the boundary: External activity and performance in organizational teams." Administrative Science Quarterly, 634-665.

Aral, S. and M. Van Alstyne

2011 "The Diversity-Bandwidth Tradeoff.” American Journal of Sociology, 117: 90-171.

Aral, S., E. Brynjolfsson, and M. Van Alstyne

2012 "Information, technology, and information worker productivity." Information Systems Research, 23: 849-867.

Austin, J. R.

1997 "A cognitive framework for understanding demographic influences in groups." International Journal of Organizational Analysis, 5: 342-359.

Axelrod, R. and D. Dion 
1988 "The further evolution of cooperation.” Science, 242: 1385-1390.

Bantel, K. A. and S. E. Jackson

1989 "Top management and innovations in banking: does the composition of the top team make a difference?” Strategic Management Journal, 10: 107-124.

Barabasi, A.-L.

2005 "The origin of bursts and heavy tails in human dynamics." Nature, 435: 207-211.

Benkler, Y.

2006 The Wealth of Networks: How Social Production Transforms Markets and Freedom. New Haven, CT: Yale University Press.

Benkler, Y.

2013 "Peer Production and Cooperation.” In J. M. Bauer and M. Latzer (eds.), Handbook on the Economics of the Internet. Cheltenham, UK: Edward Elgar.

Bettenhausen, K. L. and J. K. Murnighan

1985 "The emergence of norms in competitive decision-making groups." Administrative Science Quarterly, 30: 350-372.

Blei, D., A. Ng, and M. Jordan

2003 "Latent dirichlet allocation.” Journal of Machine Learning Research, 3: 993-1022.

Boudreau, K. J., N. Lacetera, and K. R. Lakhani

2011 "Incentives and problem uncertainty in innovation contests: An empirical analysis." Management Science, 57: 843-863.

Boudreau, K. J. and K. R. Lakhani

2013 "Using the crowd as an innovation partner." Harvard Business Review, 91: 60-9.

Burke, K. and K. Aytes

1998 "A longitudinal analysis of the effects of media richness on cohesion development and process satisfaction in computer-supported workgroups." System Sciences, 1998., Proceedings of the Thirty-First Hawaii International Conference on Vol. 1: 135-144.

Burke, K. and L. Chidambaram

1999 "How much bandwidth is enough? A longitudinal examination of media characteristics and group outcomes.” MIS Quarterly, 23: 557-579.

Burt, R. S.

1992 "The social structure of competition." Networks and Organizations: Structure, Form, and Action, 57-91. Harvard Business School Press Boston, MA.

2004 “Structural Holes and Good Ideas.” American Journal of Sociology, 110: 349-399. 
2008 "Information and structural holes: comment on Reagans and Zuckerman." Industrial and Corporate Change, 17: 953-969. Oxford Univ Press.

Butler, B., L. Sproull, S. Kiesler, and R. Kraut

2005 "Community building in online communities: Who does the work and why?" In S.

Weisband (ed.), Leadership at a distance. Mahwah, NJ: Lawrence Erlbaum Publishers.

Caruso, H. M. and A. W. Woolley

2008 "Harnessing the power of emergent interdependence to promote diverse team

collaboration.” In K. W. Phillips, E. Mannix, and M. A. Neale (eds.), Vol. 11: 245-266. Bingley, UK: Emerald Group Publishing Limited.

Centola, D. and M. Macy

2007 "Complex contagions and the weakness of long ties1." American Journal of Sociology, 113: 702-734.

Chen, H. and N. Lim

2013 “Should Managers Use Team-Based Contests?” Management Science, 59: 2823-2836.

Clotfelter, C. T.

1997 "The economics of giving." Giving better, giving smarter: Working papers of the national commission on philanthropy and civic renewal, 31-55.

Cramton, C. D.

2001 "The mutual knowledge problem and its consequences for dispersed collaboration." Organization Science, 12: 346-71.

Cramton, C. D. and P. J. Hinds

2005 "Subgroup Dynamics in Internationally Distributed Teams: Ethnocentrism or CrossNational Learning?” Research in Organizational Behavior, 26: 231-263.

Crawford, J. L. and G. A. Haaland

1972 "Predecisional information seeking and subsequent conformity in the social influence process." Journal of Personality and Social Psychology, 23: 112.

Dahlander, L. and L. Frederiksen

2012 "The Core and Cosmopolitans: A Relational View of Innovation in User Communities." Organization Science, 23: 988-1007.

Dahlander, L. and S. O’Mahony

2011 "Progressing to the Center: Coordinating Project Work." Organization Science, 22: 961979.

Ericksen, J. and L. Dyer 
2004 "Right from the start: Exploring the effects of early team events on subsequent project team development and performance.” Administrative Science Quarterly, 49: 438-471.

Espinosa, J. A., S. a. Slaughter, R. E. Kraut, and J. D. Herbsleb 2007 "Familiarity, Complexity, and Team Performance in Geographically Distributed Software Development." Organization Science, 18: 613-630.

Faraj, S., S. Jarvenpaa, and A. Majchrzak

2011 "Knowledge Collaboration in Online Communities." Organization Science, 22: 12241239.

Fischbacher, U., S. Gächter, and E. Fehr 2001 "Are people conditionally cooperative? Evidence from a public goods experiment." Economics Letters, 71: 397-404.

Frey, B. S. and R. Jegen

2001 "Motivation crowding theory." Journal of Economic Surveys, 15: 589-611.

Frey, B. S. and S. Meier

2004 'Social Comparisons and Pro-social Behavior: Testing 'Conditional Cooperation' in a Field Experiment.” American Economic Review, 94: 1717-1722.

Galegher, J. and R. E. Kraut

1994 "Computer-mediated communication for intellectual teamwork: An experiment in group writing.” Information Systems Research, 5: 110-138.

Gardner, H. K.

2012 "Performance Pressure as a Double-edged Sword: Enhancing Team Motivation but Undermining the Use of Team Knowledge.” Administrative Science Quarterly, 57: 1-46.

Gersick, C. J. G.

1989 "Marking time: Predictable transitions in task groups." Academy of Management Journal, 32: $274-309$.

Gibson, C. and J. Gibbs

2006 "Unpacking the Concept of Virtuality: The Effects of Geographic Dispersion, Electronic Dependence, Dynamic Structure, and National Diversity on Team Innovation." Administrative Science Quarterly, 51: 451-495.

Ginnett, R. C.

1993 "Crews as groups: Their formation and their leadership": 71-98. New York: Academic Press.

Goh, K.-I. and A.-L. Barabási

2008 "Burstiness and memory in complex systems." EPL (Europhysics Letters), 81: 48002. 
Haas, M. R.

2010 "The Double-Edged Swords of Autonomy and External Knowledge: Team Effectiveness in a Multinational Organization.” Academy of Management Journal, 53: 989-1008.

Hackman, J. R.

2011 Collaborative intelligence: using teams to solve hard problems. San Francisco, CA:

Berrett-Koehler Publishers.

Hackman, J. R. and G. R. Oldham

1976 "Motivation through the design of work: Test of a theory." Organizational Behavior and Human Decision Processes, 16: 250-279.

Hackman, J. R. and R. Wageman

2005 "A theory of team coaching." Academy of Management Review, 30: 269-287.

Hamilton, B. H. ., J. A. Nickerson, and H. Owan

2003 "Team Incentives and Worker Heterogeneity: An Empirical Analysis of the Impact of

Teams on Productivity and Participation.” Journal of Political Economy, 111: 465-497.

Hansen, M. T.

1999 "The search-transfer problem: The role of weak ties in sharing knowledge across organization subunits.” Administrative Science Quarterly, 44: 82-111.

Hargadon, A. and R. I. Sutton

1997 "Technology brokering and innovation in a product development firm." Administrative Science Quarterly, 42: 716-749.

Haythornthwaite, C.

2009 "Crowds and communities: Light and heavyweight models of peer production." 42nd

Hawaii International Conference on System Sciences: 1-10. Big Island, HI.

Holmstrom, B.

1982 "Moral hazard in teams." Bell Journal of Economics, 13: 324-340.

Ilgen, D. R., J. R. Hollenbeck, M. Johnson, and D. Jundt

2005 "Teams in Organizations: From Input-Process-Output Models to IMOI Models." Annual Review of Psychology, 56: 517-543.

Jackson, S., A. Joshi, and N. Erhardt

2003 "Recent Research on Team and Organizational Diversity: SWOT Analysis and Implications." Journal of Management, 29: 764-769.

Jeppesen, L. B. and K. R. Lakhani

2010 "Marginality and Problem Solving Effectiveness in Broadcast Research." Organization

Science, 31: 1016-1033. 
Jones, B. F.

2009 "The burden of knowledge and the 'death of the renaissance man': Is innovation getting harder?” Review of Economic Studies, 76: 283-317.

Karsai, M., K. Kaski, A.-L. Barabási, and J. Kertész

2012 “Universal features of correlated bursty behaviour.” Scientific Reports, 2: 397.

Kerr, N. L. and S. E. Bruun

1983 "Dispensability of member effort and group motivation losses: Free-rider effects." Journal of Personality and Social Psychology, 44: 78-94.

Kittur, A. and R. E. Kraut

2008 "Harnessing the Wisdom of Crowds in Wikipedia: Quality Through Coordination."

Proceedings of the ACM 2008 Conference on Computer Supported Cooperative Work: 37-46.

San Diego, CA.

Von Krogh, G., S. Haefliger, S. Spaeth, and M. W. Wallin

2012 "Carrots and Rainbows: Motivation and Social Practice in Open Source Software

Development.” MIS Quarterly, 36: 649-676.

Von Krogh, G. and E. von Hippel

2006 "The Promise of Research on Open Source Software.” Management Science, 52: 975983.

Lakhani, K. R. and R. G. Wolf

2005 "Why Hackers Do What They Do: Understanding Motivation and Effort in Free/Open Source Software Projects.” In J. Feller, B. Fitzgerald, S. A. Hissam, and K. R. Lakhani (eds.), Perspectives on Free and Open Source Software: 3-22. Cambridge, MA: MIT Press.

Larson, J. R.

2010 In search of synergy: In small group performance. New York, NY: Psychology Press.

Latane, B., K. Williams, and S. Harkins

1979 "Many hands make light the work: The causes and consequences of social loafing." Journal of Personality and Social Psychology, 37: 822.

Lazear, E. P.

2000 "Performance Pay and Productivity." American Economic Review, 90: 1346-1361.

Lazear, E. P. and K. L. Shaw

2007 "Personnel Economics: The Economist's View of Human Resources." Journal of

Economic Perspectives, 21: 91-114.

Lazer, D. and A. Friedman 
2007 "The network structure of exploration and exploitation." Administrative Science Quarterly, 52: 667-694.

Lerner, J. and J. Tirole

2005 "The Economics of Technology Sharing: Open Source and Beyond." Journal of Economic Perspectives, 19: 99-120.

Levine, J. M. and R. L. Moreland

2004 "Collaboration: The social context of theory development." Personality and Social Psychology Review, 8: 164-172.

Lewis, K. and B. Herndon

2011 "Transactive memory systems: Current issues and future research directions." Organization Science, 22: 1254-1265.

Lindsley, D. H., D. J. Brass, and J. B. Thomas

1995 "Efficacy-Performance Spirals: A Multilevel Perspective.” Academy of Management Review, 20: 645-678.

Malmgren, R. D., D. B. Stouffer, A. E. Motter, and L. A. N. Amaral 2008 "A Poissonian explanation for heavy tails in e-mail communication." Proceedings of the National Academy of Sciences, 105: 18153-18158.

Malone, T. W. and K. Crowston

1994 "The Interdisciplinary Study of Coordination.” ACM Computing Surveys, 26: 87-119.

Manso, G.

2011 “Motivating innovation.” Journal of Finance, 66: 1823-1860.

Massey, A. P., M. M. Montoya-Weiss, and Y.-T. Hung

2003 "Because time matters: Temporal coordination in global virtual project teams." Journal of Management Information Systems, 19: 129-155.

McDonough, E. F., K. B. Kahnb, and G. Barczaka

2001 "An investigation of the use of global, virtual, and colocated new product development teams." Journal of Product Innovation Management, 18: 110-120.

McGrath, J. E.

1991 "Time, Interaction, and Performance (TIP): A Theory of Groups." Small Group Research, 22: 147.

McLeod, P. L., S. A. Lobel, and T. H. Cox

1996 "Ethnic diversity and creativity in small groups." Small Group Research, 27: 248-264.

Messick, D. M. 
1999 "Alternative logics for decision making in social settings." Journal of Economic Behavior \& Organization, 39: 11-28.

Montgomery, J. D.

1991 "Social networks and labor-market outcomes: Toward an economic analysis." American Economic Review, 81: 1408-1418.

Montoya-Weiss, M. M., A. P. Massey, and M. Song

2001 "Getting it together: Temporal coordination and conflict management in global virtual teams." Academy of Management Journal, 1251-1262.

Murphy, E.

2004 "Recognising and promoting collaboration in an online asynchronous discussion." British Journal of Educational Technology, 35: 421-431.

Murray, F. and S. O'Mahony

2007 "Exploring the Foundations of Cumulative Innovation: Implications for Organization Science.” Organization Science, 18: 1006-1021.

Nelson, R. R.

1959 "The economics of invention: A survey of the literature." Journal of Business, 101-127.

O'Leary, M. B. and J. N. Cummings

2007 "The spatial, temporal, and configurational characteristics of geographic dispersion in work teams.” MIS Quarterly, 31: 433-452.

O’Leary, M. B. and M. Mortensen

2010 "Go (Con)figure: Subgroups, Imbalance, and Isolates in Geographically Dispersed

Teams.” Organization Science, 21: 115-131.

O'Mahony, S. and F. Ferraro

2007 "The Emergence of Governance in an Open Source Community." Academy of

Management Journal, 50: 1079-1106.

Ocker, R., S. R. Hiltz, M. Turoff, and J. Fjermestad

1995 "The Effects of Distributed Group Support and Process Structuring on Software

Requirements Development Teams: Results on Creativity and Quality." Journal of Management Information Systems, 12: 127-153.

Olson, J. S. and G. M. Olson

2014 Working together apart: Collaboration over the internet. Morgan \& Claypool.

Parker, G. and M. Van Alstyne

2012 “Innovation, Openness, and Platform Control." Proceedings of ICIS 2008.

Paulus, P. 
2000 "Groups, Teams, and Creativity: The Creative Potential of Idea-generating Groups." Applied Psychology, 49: 237-262.

Pieterse, A. N., D. van Knippenberg, and D. van Dierendonck

2012 "Cultural Diversity and Team Performance: The Role of Team Member Goal

Orientation." Academy of Management Journal, 56: 782-804.

Preece, J. and B. Shneiderman

2009 "The Reader-to-Leader Framework: Motivating Technology-Mediated Social

Participation.” AIS Transactions on Human-Computer Interaction, 1: 13-32.

Prendergast, $\mathrm{C}$.

1999 "The provision of incentives in firms." Journal of Economic Literature, 37: 7-63. JSTOR.

Rabin, M.

1993 "Incorporating fairness into game theory and economics." American Economic Review, 83: $1281-1302$.

Reagans, R., E. Zuckerman, and B. McEvily

2004 "How to Make the Team: Social Networks vs. Demography as Criteria for Designing Effective Teams.” Administrative Science Quarterly, 49: 101-133.

Reagans, R. and E. W. Zuckerman

2001 "Networks, diversity, and productivity: The social capital of corporate R\&D teams." American Economic Review, 12: 502-517.

Robert, L. P., a. R. Dennis, and M. K. Ahuja

2008 "Social Capital and Knowledge Integration in Digitally Enabled Teams." Information Systems Research, 19: 314-334.

Roberts, J. A., I.-H. Hann, and S. A. Slaughter

2006 "Understanding the motivations, participation, and performance of open source software developers: A longitudinal study of the Apache projects.” Management Science, 52: 984-999.

Rochet, J.-C. and J. Tirole

2006 "Two-sided markets: a progress report." RAND Journal of Economics, 37: 645-667.

Seidel, M. -D. L., and K. Stewart

2011 "An Initial Description of the C-form." Research in the Sociology of Organizations, Volume 33(37-72).

Sharda, R., S. H. Barr, and J. C. McDonnell

1988 "Decision support system effectiveness: a review and an empirical test." Management Science, 34: 557-579.

Shin, S. J., T.-Y. Kim, J.-Y. Lee, and L. Bian 
2012 "Cognitive Team Diversity and Individual Team Member Creativity: A Cross-Level Interaction.” Academy of Management Journal, 55: 197-212.

Stephan, P. E.

1996 "The Economics of Science." Journal of Economic Literature, 34: 1199-1235.

Surowiecki, J. and M. P. Silverman

2007 "The wisdom of crowds." American Journal of Physics, 75: 190.

Swedberg, R.

1991 "Major traditions of economic sociology." Annual Review of Sociology, 17: 251-276.

Thompson, J. D.

2003 Organizations in action. New York, NY: McGraw-Hill.

Uzzi, B., S. Mukherjee, M. Stringer, and B. Jones

2013 "Atypical Combinations and Scientific Impact." Science, 342: 468-472. American

Association for the Advancement of Science.

Wageman, R. and F. M. Gordon

2005 "As the twig is bent: How group values shape emergent task interdependence in groups." Organization Science, 16: 687-700.

Walker, G., B. Kogut, and W. Shan

1997 "Social capital, structural holes and the formation of an industry network." Organization Science, 8: 109-125.

Warkentin, M. E., L. Sayeed, and R. Hightower

1997 "Virtual Teams versus Face-to-Face Teams: An Exploratory Study of a Web-based

Conference System." Decision Sciences, 28: 975-996.

Woolley, A. W., C. F. Chabris, A. Pentland, N. Hashmi, and T. W. Malone

2010 "Evidence for a Collective Intelligence Factor in the Performance of Human Groups."

Science, 330: 686-688.

Wooten, J. O. and K. T. Ulrich

2012 "Idea Generation and the Role of Feedback: Evidence from Field Experiments with Innovation Tournaments."

$\mathrm{Wu}, \mathrm{L}$.

2013 "Social network effects on productivity and job security: Evidence from the adoption of a social networking tool." Information Systems Research, 24: 30-51.

Wuchty, S., B. F. Jones, and B. Uzzi

2007 "The increasing dominance of teams in production of knowledge." Science, 316: 10361039. 
Zaheer, A. and G. G. Bell

2005 "Benefiting from network position: firm capabilities, structural holes, and performance." Strategic Management Journal, 26: 809-825. 